\title{
Evaluation of Plant Growth on Expanded Black Cotton Soil
}

\author{
Samwel Nyakach $^{1}$, Seth F.O. Owido ${ }^{2} \&$ Japheth O. Onyando $^{1}$ \\ ${ }^{1}$ Department of Agricultural Engineering, Egerton University, Njoro, Kenya \\ ${ }^{2}$ Department of Crops, Horticulture and Soils, Egerton University, Njoro, Kenya \\ Correspondence: Samwel Nyakach, Department of Agricultural Engineering, Egerton University, Njoro, Kenya. \\ E-mail: nyakachsam@gmail.com
}

Received: December 6, 2017 Accepted: December 29, 2017 Online Published: February 1, 2018

doi:10.5539/sar.v7n2p41 URL: https://doi.org/10.5539/sar.v7n2p41

\begin{abstract}
In aggregate hydroponics, the suitability of a particular medium is often guided by its physical properties. However these may not provide adequate evaluation. By growing a crop, the growth characteristics can also be used to guide medium preparation and selection. Tomatoes (Anna Fl variety) were grown in containers under a greenhouse and provided with equal amount of nutrient solution. The expanded black cotton soil was prepared by mixing with rice husk at a ratio of $90: 10$, fired at $750^{\circ} \mathrm{C}$ for 30 minutes and size reduced to various textures. The crops planted in the expanded clay aggregates performed better than the black cotton soil both in terms of stem elongation and enlargement due to improved drainage, nutrient flow and aeration conditions. The root length density was $25654 \mathrm{~m} \mathrm{~m}^{-3}$ in black cotton soil, being the highest and lowest in the coarse aggregates which had $9433 \mathrm{~m} \mathrm{~m}^{-3}$.
\end{abstract}

Keywords: hydroponic medium, stem growth, root length density

\section{Introduction}

Expanded clay has been applied in various forms to aggregate hydroponic systems. These systems use inert solid material which has most of the desirable physical properties of soil such as, being friable, good water holding properties, easily aerated and well drained. The growing medium cannot grow anything on its own since it does not supply plant nutrients. The nutrients are supplied to the plants by a nutrient solution. One of the most commonly adopted methods of preparing expanded clay aggregates involves forming round pellets out of clay in rotary kilns at about $1200^{\circ} \mathrm{C}$. This causes the clay to expand and become porous resulting in pellets which are inert, lighter in weight and does not compact over time (Singh, 2009).

In this study the aggregate medium was prepared using black cotton soil mixed with rice husk at a ratio of 90:10 by mass and then fired at $750{ }^{\circ} \mathrm{C}$ for 30 minutes. The resulting material was the size reduced and tested for various physical properties. Nyakach et al. (2017) concluded that black cotton soils can be converted into aggregate hydroponic medium in this way thus improving on its physical characteristics to make it light weight with low bulk density, enabling it to remain loose and friable over wide ranges of moisture contents, drain easily and have moderate permeability to permit water and nutrient movement through it. These parameters may however not adequately describe the performance of the expanded black cotton soil as a plant growth medium hence the need for further evaluation in terms of effect on stem growth and root development. Root and stem growth are affected by the composition and texture of the medium (Maloof, 2004). Root length density (RLD) is a critical factor in determining the crops potential to uptake water and nutrients. RLD can be affected by irrigation method, growing medium texture and bulk density (Rangjian et al., 2017). Water and nutrients taken up by the roots are transferred to the leaves through the stem for use in photosynthesis. The roots also provide anchorage to the plant. The root system has also been found to have more surface area than the shoot system (Wahome et al., 2011).

\section{Materials and the Methods}

The experiment was carried out at Egerton University's Tatton Farm. The area is located $00^{\circ} 22^{\prime}$ South of the equator, $35^{\circ} 55^{\prime}$ East and $2286 \mathrm{~m}$ above sea level. The experimental site receives an average annual rainfall of $1200 \mathrm{~mm}$, and the averages of temperatures in the field ranges between 10.2 and $22.0^{\circ} \mathrm{C} \mathrm{(Ng'etich} \mathrm{et} \mathrm{al.,} \mathrm{2014).}$ The experimental trial was carried out using tomato crop (Solanum lycopersicum) grown in a greenhouse. Growth factors such as root length density (RLD), stem diameter and height were measured. 
The expanded clay was categorized as fine aggregates, coarse aggregates and a mix of fine and coarse aggregates. The fines had particle sizes corresponding to fine sand ranging from $0.075-0.85 \mathrm{~mm}$, while the sizes for the coarse aggregates ranged between $0.85-2.00 \mathrm{~mm}$. The mixed size aggregates comprised of materials greater than $2 \mathrm{~mm}$ and those less than $0.075 \mathrm{~mm}$ at a ratio of $10 \%$ each. The remaining $80 \%$ was materials within the $0.75 \mathrm{~mm}-2.00 \mathrm{~mm}$ size range. The black cotton soil (clay) was also used as sampled from Kenya Agricultural and Livestock Research Organization (KALRO) field in Kibos, Kisumu. The area lies within the Kano plains in Kenya. The soil sample had the following particle size distribution as given in table 1.

Table 1. Textural analysis of black cotton soil

\begin{tabular}{lc}
\hline Particle size (mm) & Proportion (\%) \\
\hline$>2.0$ & 0.7 \\
$0.85-2$ & 5.7 \\
$0.075-0.85$ & 27.2 \\
$<0.075$ & 66.4 \\
\hline
\end{tabular}

The crops were planted in one-liter containers, each supplied with an average $130 \mathrm{ml}$ of the nutrient solution daily throughout the growing period. The containers were perforated on the sides and at the bottom to enhance aeration and free drainage. They were placed in a single row, buried into the soil to provide better support. Figures $1 \mathrm{a}$ and $1 \mathrm{~b}$ show the setup at various stages of the experiment.

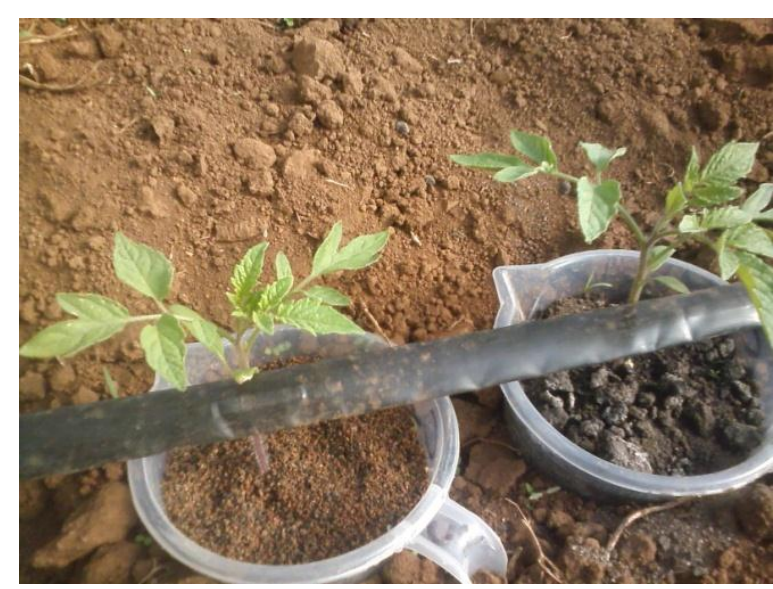

Figure 1. (a) Crop at transplanting

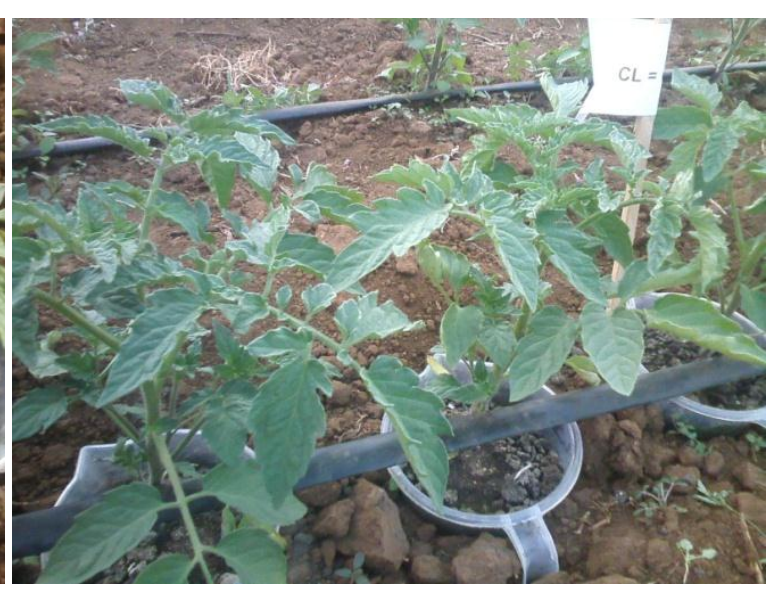

(b) Established tomato crop

The hydroponic nutrients were obtained from Hydroponics Africa with the following nutrient composition;

Table 2. Composition of the nutrient feed before dilution

\begin{tabular}{lll}
\hline Nutrient & Symbol & Parts per million \\
\hline 0.02\% Potassium & $\mathrm{K}_{2} \mathrm{O}$ & 153 \\
Copper proteinate & $\mathrm{Cu}$ & 0.2 \\
Zinc proteinate & $\mathrm{Zn}$ & 0.3 \\
Boron proteinate & $\mathrm{B}$ & 0.7 \\
Calcium & $\mathrm{Ca}$ & 126 \\
Manganese proteinate & $\mathrm{Mn}$ & 1.97 \\
Phosphate & $\mathrm{P}$ & 50 \\
Iron proteinate & $\mathrm{Fe}$ & 28 \\
Magnesium & $\mathrm{Mg}$ & 48 \\
Nitrogen & $\mathrm{N}$ & 120 \\
\hline
\end{tabular}

The nutrients are packaged as Hydro A and Hydro B and each was mixed at a rate of $2 \mathrm{~g}$ per liter of water. The nutrient solution was supplied from a raised tank through drip lines to each plant.

The plant stem diameter and height were measured weekly. The stem height was measured using a meter rule with the measurements taken from the border of the container to the top of the main plant stem while the 
diameters were measured using a vernier caliper. The first readings were taken 12 days after transplanting. This was to allow proper establishment of the seedlings. RLD was determined at the end of the trial period when the crops started to flower after six weeks. The total length of the roots was obtained by carefully cleaning off the medium and measuring the length of individual roots.

\section{Results and Discussion}

The results shown in table 3 were obtained from the stem diameter (D) and height (H) measurements. Subscripts 0 - 5 indicate the number of weeks elapsed since commencement of data collection.

Table 3. Measurements of stem diameter and height

\begin{tabular}{lllllllllllll}
\hline sample & D0 & H0 & D1 & H2 & D2 & H2 & D3 & H3 & D4 & H4 & D5 & H5 \\
\hline C1 & 0.19 & 6.05 & 0.36 & 10.07 & 0.49 & 16.48 & 0.67 & 24.5 & 0.69 & 37.5 & 0.75 & 55.9 \\
C2 & 0.28 & 11.6 & 0.45 & 16.02 & 0.58 & 22.32 & 0.67 & 32.5 & 0.74 & 48 & 0.83 & 71.1 \\
C3 & 0.3 & 11 & 0.47 & 15.66 & 0.57 & 20.53 & 0.7 & 36.5 & 0.77 & 51 & 0.85 & 68.6 \\
CL1 & 0.34 & 10.1 & 0.48 & 15.17 & 0.73 & 22.34 & 0.7 & 34.5 & 0.84 & 50 & 1.01 & 69.9 \\
CL2 & 0.24 & 8.1 & 0.45 & 14.46 & 0.6 & 19.54 & 0.68 & 29.8 & 0.7 & 39 & 0.71 & 50.8 \\
CL3 & 0.32 & 10.7 & 0.58 & 16.6 & 0.64 & 22.24 & 0.75 & 32.2 & 0.74 & 41 & 0.89 & 61.0 \\
CL4 & 0.33 & 11.2 & 0.5 & 16.93 & 0.61 & 24.04 & 0.72 & 36.2 & 0.81 & 52 & 0.94 & 73.7 \\
M1 & 0.3 & 10.8 & 0.49 & 15.25 & 0.6 & 22.69 & 0.68 & 38.1 & 0.71 & 54 & 0.79 & 71.1 \\
M2 & 0.27 & 10.6 & 0.51 & 15.31 & 0.62 & 20.73 & 0.72 & 37.8 & 0.78 & 51 & 0.87 & 69.9 \\
M3 & 0.27 & 10.7 & 0.47 & 15.76 & 0.57 & 19.01 & 0.69 & 34.7 & 0.73 & 46 & 0.76 & 68.6 \\
M4 & 0.2 & 8.8 & 0.41 & 12.23 & 0.6 & 22.34 & 0.65 & 32.2 & 0.66 & 46 & 0.77 & 63.5 \\
F1 & 0.35 & 8.8 & 0.6 & 14.89 & 0.73 & 24.61 & 0.78 & 36.8 & 0.82 & 53 & 0.92 & 78.7 \\
F2 & 0.32 & 9.8 & 0.48 & 13.85 & 0.63 & 21.02 & 0.7 & 34.9 & 0.74 & 48 & 0.83 & 71.1 \\
F3 & 0.25 & 7.7 & 0.49 & 13.6 & 0.66 & 21.24 & 0.7 & 34.5 & 0.86 & 55 & 0.94 & 78.7 \\
\hline
\end{tabular}

$\mathrm{C}$ - coarse aggregates; $\mathrm{CL}$ - black cotton soil; $\mathrm{M}$ - mixed aggregates; $\mathrm{F}$ - fine aggregates.

From these results, the percent change in stem height (elongation) and diameter (enlargement) was determined and averaged over the test period as given in tables 4 and 5 respectively.

Table 4. Percent changes in stem height

\begin{tabular}{lccccccc}
\hline \multirow{2}{*}{ Sample } & \multicolumn{6}{c}{ Weekly stem elongation rates } & \multicolumn{3}{c}{ Mean weekly growth rate } \\
\cline { 2 - 9 } & Wk1 & Wk2 & Wk3 & Wk4 & Wk5 & Per sample & Av. (\%) \\
\hline C1 & 0.66 & 0.64 & 0.49 & 0.53 & 0.49 & 0.56 & \\
C2 & 0.38 & 0.39 & 0.46 & 0.48 & 0.48 & 0.44 & \\
C3 & 0.42 & 0.31 & 0.78 & 0.40 & 0.35 & 0.45 & 48.3 \\
\hline CL1 & 0.50 & 0.47 & 0.54 & 0.45 & 0.40 & 0.47 & \\
CL2 & 0.79 & 0.35 & 0.53 & 0.31 & 0.30 & 0.45 & \\
CL3 & 0.55 & 0.34 & 0.45 & 0.27 & 0.49 & 0.42 & \\
CL4 & 0.51 & 0.42 & 0.51 & 0.44 & 0.42 & 0.46 & 45.2 \\
\hline M1 & 0.41 & 0.49 & 0.68 & 0.42 & 0.32 & 0.46 & \\
M2 & 0.44 & 0.35 & 0.82 & 0.35 & 0.37 & 0.47 & \\
M3 & 0.47 & 0.21 & 0.83 & 0.33 & 0.49 & 0.46 & \\
M4 & 0.39 & 0.83 & 0.44 & 0.43 & 0.38 & 0.49 & 47.2 \\
\hline F1 & 0.69 & 0.65 & 0.50 & 0.44 & 0.48 & 0.55 & \\
F2 & 0.41 & 0.52 & 0.66 & 0.38 & 0.48 & 0.48 & \\
F3 & 0.77 & 0.56 & 0.62 & 0.59 & 0.43 & 0.51 & 51.4 \\
\hline
\end{tabular}

The plants grown in fine aggregates of the expanded clay had the highest mean weekly stem elongation rate of $51.4 \%$. This could be attributed to better water holding capacity, nutrient flow and root contact. The black cotton soil had the least stem elongation at an average weekly rate of $45.2 \%$ attributed to poor drainage and aeration conditions. 
Table 5. Changes in stem diameter

\begin{tabular}{llllllll}
\hline Sample & \multicolumn{9}{c}{ Weekly stem enlargement rates } & \multicolumn{3}{c}{ Mean weekly growth rate } \\
\cline { 2 - 8 } & Wk1 & Wk2 & Wk3 & Wk4 & Wk5 & Per sample & $(\%)$ \\
\hline C1 & 0.89 & 0.36 & 0.37 & 0.03 & 0.09 & 0.348 & \\
C2 & 0.61 & 0.29 & 0.16 & 0.10 & 0.12 & 0.255 & 28.2 \\
C3 & 0.57 & 0.21 & 0.23 & 0.10 & 0.10 & 0.242 & \\
\hline CL1 & 0.41 & 0.52 & -0.04 & 0.20 & 0.20 & 0.259 & \\
CL2 & 0.88 & 0.33 & 0.13 & 0.03 & 0.01 & 0.277 & \\
CL3 & 0.81 & 0.10 & 0.17 & -0.01 & 0.20 & 0.255 & \\
CL4 & 0.52 & 0.22 & 0.18 & 0.13 & 0.16 & 0.240 & \\
\hline M1 & 0.63 & 0.22 & 0.13 & 0.04 & 0.11 & 0.230 & \\
M2 & 0.89 & 0.22 & 0.16 & 0.08 & 0.12 & 0.293 & \\
M3 & 0.74 & 0.21 & 0.21 & 0.06 & 0.04 & 0.253 & \\
M4 & 1.05 & 0.46 & 0.08 & 0.02 & 0.17 & 0.356 & \\
\hline F1 & 0.71 & 0.22 & 0.07 & 0.05 & 0.12 & 0.235 & \\
F2 & 0.50 & 0.31 & 0.11 & 0.06 & 0.12 & 0.220 & \\
F3 & 0.96 & 0.35 & 0.06 & 0.23 & 0.09 & 0.338 & \\
\hline
\end{tabular}

The plants grown in the coarse and mixed size aggregates had higher weekly growth in stem diameter of $28 \%$. This could be attributed to improved water and nutrient flow, better drainage and aeration. The black cotton soil had the least change of $25.8 \%$. This is because clay although has high total available water, the bulk of this water is not readily available for uptake by plant. From week two there is a decline in stem enlargement rate in all the samples due to development of more leaves hence higher evapotranspiration rates. The decline is more pronounced in black cotton soil between weeks three and four after which the crop seems to recover as the roots spread deeper into the soil.

The RLD was computed from equation 1 and the mean values presented in table 6 below;

$$
R L D=\frac{L_{r}}{V_{m}}
$$

Where; $R L D=$ root length density

$L_{r}=$ total length of the roots

$V_{m}=$ medium volume given by the product of cross sectional area of the container and the maximum rooting depth.

Table 6. Root length density

\begin{tabular}{lll}
\hline Sample & Total root length $(\mathbf{m m})$ & Root length density $\left(\mathbf{m ~ m}^{\mathbf{- 3}}\right)$ \\
\hline C & 9433 & 9433 \\
CL & 25654 & 25654 \\
M & 18936 & 18936 \\
F & 17019 & 17019 \\
\hline
\end{tabular}

Since the crops were planted in containers, the RLD was generally high for all the samples. This is because RLD tends to be higher at depths between 0 to $20 \mathrm{~cm}$ and decreases down the profile. Under drip irrigation, 70-75\% of the total RLD of tomatoes is concentrated in $0-15 \mathrm{~cm}$ soil layers because of the high irrigation frequencies. Smaller soil volumes also tend to give higher RLD values (Rangjian et al., 2017; de Azevedo et al., 2011). The containers concentrated the roots within the limited space resulting in increase in RLD. In this study coarse aggregates had the lowest RLD value. The finer aggregates had numerous small pore spaces which encouraged the development of more root hairs. The plants in black cotton soil had the highest RLD hence providing more surface area to be able to extract the nutrient feed. This is response to water stress due lower readily available water in clays. For the expanded clay, the mixed aggregates had high RLD. Mixing fine and coarse aggregates makes the medium to have proportionate ratio of micro and micro pores hence moderate drainage and water holding capacities. Considering both root and stem development, black cotton soil performed well under the test 
conditions provided. The unsuitability of this soil type often becomes evident when subjected to extremes of moisture content presented during excess wetness or lack of moisture (Nyakach, 2017).

\section{Conclusion}

Plant growth in a hydroponic system is affected by the type of aggregate media used. In expanded black cotton soil, the texture affected both root development and stem growth. This because the tomato crop requires good drainage and aeration conditions. Using expanded black cotton soil improves the performance of the crop in terms of stem elongation and enlargement. The reduced RLD is beneficial since the plant roots can be accommodated in small containers and the spacing between plants can be reduced.

\section{References}

de Azevedo, M. C. B., Jean, Louis, Chopart, J, L., \& Medina, C. C. (2011). Sugarcane root length density and distribution from root intersection counting on a trench-profile. Science and Agriculture, 68(1). https://doi.org/10.1590/S0103-90162011000100014

Maloof, J. N. (2004). Plant Development: Slowing Root Growth Naturally. Current Biology, 14, 395-396. https://doi.org/10.1016/j.cub.2004.05.016

Ng'etich, O. K., Aguyoh, J. N., \& Ogweno, J. O. (2014). The Effect of Integrated Application of Farmyard Manure and Calcium Ammonium Nitrate on Growth and Yield Attributes of African Nightshade (Solanum Scabrum Mill.) Asian Journal of Agriculture and Food Science, 2(2). https://www.researchgate.net/publication/272495028

Nyakach, S., Onyando, J. O., \& Owido, S. F. O. (2017). Evaluation of Expanded Black Cotton Soil as a Hydroponic Medium. World Journal of Agricultural Research, 5(2), 88-93.

Nyakach, S., Owido, S. F. O., \& Onyando, J. O. (2017). Effect of Firing Time and Temperature on Selected Physical Properties of Black Cotton Soil. Journal of Agricultural Science and Engineering, 3(1), 1-12. American Institute of Science.

Rangjian, Q., Taisheng, D., \& Shaozhong, K. (2017). Root length density distribution and associated soil water dynamics for tomato plants under furrow irrigation in a solar greenhouse. Journal of Arid Land, 9(5), 637-650. https://doi.org/10.1007/s40333-017-0064-9

Singh, D. (2009). Hydoponics - Soilless Culture of Plants. Agrobios, India. 163pp.

Wahome, K., Musarirambi, M. T., \& Shongwe, V. D. (2011). Effects of Different Hydroponics Systems and Growing Media on the Vegetative growth, Yield and Cut Flower Quality of Gypsophila. World Journal of Agricultural Sciences, 7(6), 692-698.

\section{Copyrights}

Copyright for this article is retained by the author(s), with first publication rights granted to the journal.

This is an open-access article distributed under the terms and conditions of the Creative Commons Attribution license (http://creativecommons.org/licenses/by/3.0/). 